\title{
INVENTÁRIO NEGATIVO JUDICIAL E EXTRAJUDICIAL: CONSELHO NACIONAL DE JUSTIÇA
}

\section{JUDICIAL AND EXTRAJUDICIAL NEGATIVE INVENTORY: NATIONAL COUNCIL OF JUSTICE}

\author{
Léia Comar Riva ${ }^{1}$ \\ Rogério Nogueira Guimarães ${ }^{2}$
}

Inventário é a declaração do conhecimento, em que se descreve e enumera ou só se descreve o que se encontrou. (PONTES DE MIRANDA, 1984, p. 194).

\section{RESUMO}

O presente estudo tem como objetivo refletir sobre o inventário negativo, as situações excepcionais que o justificam e a sua normatização junto à legislação, à doutrina, à jurisprudência e ao Conselho Nacional de Justiça (CNJ). O procedimento metodológico constitui-se de pesquisas bibliográfica e documental, fundadas na discussão teórica do material levantado. Após a análise, verifica-se que no inventário negativo não se visa inventariar nada; o que se procura é, tão somente, obter uma sentença homologatória que, após citados os herdeiros, caso não haja impugnação, pedido de colação ou alegação de bens sonegados, declare não haver o que inventariar. A discussão acerca da possibilidade ou não do inventário negativo encontra-se superada, uma vez que os dados apontaram, com clareza, que apesar de o inventário negativo judicial ou extrajudicial não ser recepcionado pela legislação brasileira, na praxe, ele encontra guarida na doutrina, na jurisprudência e no art. 28 da Resolução n. 35/2007 do Conselho Nacional de Justiça (CNJ).

Palavras-chave: Herdeiros. Inexistência de bens. Inventário.

\footnotetext{
${ }^{1}$ Pós Doutora em Direito pela Universidade de Coimbra - Ius Gentium Conimbrigae - Centro de Direitos Humanos Faculdade de Direito (UC-FD) Portugal. Doutora em Direito Civil pela Faculdade de Direito do Largo de São Francisco (FD-USP); mestre em Ciências (FFCLRP-USP); especialista em Violência Doméstica contra Criança e Adolescente (IP-USP). Professora Efetiva de Direito Civil: Família e Sucessões do Curso de Direito e de Especialização em Direitos Humanos da Universidade Estadual de Mato Grosso do Sul (UEMS), Unidade Universitária de Paranaíba-MS. Pesquisadora e membro do Grupo de Estudo e Pesquisa GREDIFAMS. Associada do Instituto Brasileiro de Direito de Família (IBDFAM). Membro-associado da Academia Brasileira de Direito Civil (ABDC). Universidade Estadual de Mato Grosso do Sul - Unidade Universitária de Paranaíba - Brasil. Lattes: http://lattes.cnpq.br/0537816724202557 E-mail: lcriva@uems.br

2 Doutor em Direito pela Pontifícia Universidade Católica de São Paulo - PUC/SP, Área de Concentração: Efetividade do Direito. Mestre em Direito pelo Centro Universitário Toledo de Araçatuba-SP (UNITOLEDO), na Área de Concentração: Prestação Jurisdicional no Estado Democrático de Direito. Especialista em Direito Processual pela Universidade Paulista, São Paulo-SP (2001). Possui graduação em Direito pela Universidade Estadual de Mato Grosso do Sul. Professor Adjunto do Curso de Direito da Universidade Estadual de Mato Grosso do Sul/UEMS. Oficial Substituto do Serviço de Registro de Imóveis e Tabelionato de Protesto de Títulos da Comarca de Aparecida do Taboado-MS. Universidade Estadual de Mato Grosso do Sul - Unidade Universitária de Paranaíba - Brasil. Lattes: http://lattes.cnpq.br/0295057781995793 E-mail: lcriva@uems.br
} 


\begin{abstract}
This study aims to reflect on the negative inventory, the exceptional situations that justify it and its standardization with legislation, doctrine, jurisprudence and the National Council of Justice (CNJ). The methodological procedure consists of bibliographic and documentary research, based on the theoretical discussion of the material raised. After the analysis, it is verified that in the negative inventory it is not intended to inventory anything; what is sought is, only, to obtain an approval judgment that, after the heirs are cited, if there is no challenge, request for bonding or allegation of evaders, declare that there is nothing to inventory. The discussion about the possibility or not of the negative inventory is overcome, since the data clearly pointed out that although the negative judicial or extrajudicial inventory is not received by Brazilian legislation, in practice, it finds shelter in doctrine, jurisprudence and art. 28 of Resolution $n$. 35/2007 of the National Council of Justice (CNJ).
\end{abstract}

Keywords: Heirs. No assets. Inventory.

\title{
INTRODUÇÃO
}

A morte de uma pessoa pode acarretar, para o sucessor ou não, determinados direitos e deveres. Isso ocorre em situações como aquelas em que, mesmo diante da inexistência de bens deixados pelo de cujus, o cônjuge sobrevivente almeja constituir novas núpcias e não realizou o inventário, ou quando o credor de falecido cobra dívida ou alguma prestação contraída pelo defunto em vida. Para essas situações, o melhor caminho é proceder ao inventário negativo, a fim de resguardar direitos ao certificar a inexistência de bens do falecido a partilhar.

Nosso ordenamento jurídico pátrio prevê o inventário judicial e extrajudicial, mas não faz menção ao inventário negativo. Apesar disso, na prática, o inventário sem bens a declarar continua em uso, inclusive em sua versão extrajudicial.

O presente estudo visa refletir acerca do inventário negativo, as situações excepcionais que o justificam e a sua normatização junto à legislação, à doutrina, à jurisprudência e ao Conselho Nacional de Justiça (CNJ).

O procedimento metodológico constitui-se de pesquisas bibliográfica e documental; a análise interpretativa fundar-se-á "na discussão teórica das normas ou categorias jurídicas abstratas”. (SEVERINO, 1979, p. 60-62; ECO, 2010, p. 42; MARCHI, 2009, p. 66).

Para a investigação, far-se-ão algumas considerações no que diz respeito ao instituto jurídico do inventário e suas modalidades e ao inventário negativo e as recorrentes situações extraordinárias que podem justificá-lo. Em seguida, buscar-se-á refletir acerca das determinações advindas do Conselho Nacional de Justiça quanto à possibilidade de proceder ao 
inventário negativo e ao inventário negativo extrajudicial. Ao final serão apresentados os resultados do presente estudo.

\section{ORDENAMENTO JURÍDICO BRASILEIRO: INVENTÁRIO E SUAS MODALIDADES}

Inventário, no sentido etimológico, "deriva do latim inventarium, de invenire (agenciar, diligenciar, promover)" e em sentido amplo significa "o processo ou a série de atos praticados com o objetivo de ser apurada a situação econômica de uma pessoa ou de uma instituição, pelo relacionamento de todos os seus bens e direitos, ao lado de um rol de todas as suas obrigações e encargos". (SILVA, 1982, p. 515, itálicos do autor).

Pontes de Miranda (1984, p. 193) explica, de acordo com o Dicionário da Língua Portuguesa, que inventário é o "registro, rol, catálogo, que se faz dos bens, que o defunto deixa, ou dos bens, e móveis de algum vivo" e o Dicionário Jurídico anota que é "têrmo de prática, que significa em geral a descrição de alguma coisa. Diz-se, porém, particularmente, de numeração e descrição de bens móveis e de raiz, títulos, papéis, e dívidas ativas e passivas do defunto".

No tocante ao inventário judicial, Pontes de Miranda (1984, p. 197) elucida que é "a forma mais adequada a sistemas jurídicos em que é limitada, por lei, a responsabilidade dos herdeiros e, por lei, assegurada a separatio, a favor dos credores". Ainda, segundo o Mestre, as legislações da época, Código Civil de 1916 e Código de Processo Civil de 1973, embora permitissem a partilha amigável por escritura pública, termo nos autos ou escrito particular, homologado pelo juiz não facultavam a possibilidade do inventário extrajudicial. Nesse diapasão, a "parte final do Código de Processo Civil, art. 465, teve por fito cortar cerce qualquer interpretação no sentido de se permitir inventário extrajudicial. Êsse, se foi feito, é nulo. Não vale sequer, como contrato de direito privado". (PONTES DE MIRANDA, 1984, p. 197, itálicos do autor).

Considera-se inventário, em nosso direito sucessório atual, o procedimento que reúne os elementos relativos à abertura da sucessão em razão "da morte de uma pessoa, sua herança, suas dívidas, seus herdeiros e legatórios, a fim de, após atender o pagamento dos débitos exigíveis e resolver as questões suscitadas de direito ou de fato, ser ultimada a partilha, pondo termo a comunhão hereditária”. (PACHECO, 2005, p. 433). O inventário é o processo judicial, de acordo com os artigos 1.796 do Código Civil e 610, caput, do Código de Processo Civil, que 
visa à "relação, descrição, avaliação e liquidação de todos os bens pertencentes ao de cujus ao tempo de sua morte, para distribuí-los entre seus sucessores”. (DINIZ, 2018, p. 420).

O inventário judicial, de acordo com a legislação, processa-se mediante três ritos distintos: inventário judicial pelo rito tradicional (inventário comum), cabível diante da existência de herdeiros incapazes ou testamento (arts. 610 a 658, Código de Processo Civil) ${ }^{3}$, o inventário judicial pelo rito de arrolamento sumário, admissível quando todos os interessados forem maiores e capazes, abrange bens de qualquer valor e a partilha terá que ser amigável (arts. 659 a 663, Código de Processo Civil) ${ }^{4}$ e inventário judicial pelo rito do arrolamento comum (arts. 664 e 665 Código de Processo Civil), ${ }^{5}$ oportuno se os bens do espólio forem de reduzido valor (1.000 salários mínimos), mesmo que as partes sejam incapazes ou ausentes.

Assinala-se arrolamento um “processo de inventário simplificado' e célere, caracterizado pela redução de atos formais ou de solenidade". (DINIZ, 2018, p. 442). É “forma simplificada de inventário-partilha, pela redução dos atos procedimentais e abreviação dos prazos". Apesar de visar à rapidez e à economia do processo, ele não "dispensa a intervenção judicial, em face dos interesses de terceiros, na liquidação da herança, mas agiliza o procedimento, com sua abreviação, em casos especiais”. (OLIVEIRA; AMORIM, 2013, p. $395)$.

Segundo o disposto no Código de Processo Civil de 2015 (Livro I, Título III, Capítulo VI) o inventário e a partilha são procedimentos especiais de "jurisdição contenciosa, aplicandose lhes todos os princípios gerais do processo concernentes as partes, atos processuais, formação, suspensão e extinção do processo, sistema recursal e preclusões, efeitos da sentença e incidência da coisa julgada". (DINIZ, 2018, p. 420).

Existe, ainda, o inventário extrajudicial, também conhecido por via administrativa ou por escritura pública, cabível quando os herdeiros forem capazes e concordes e o falecido não tiver deixado testamento; as partes devem estar assistidas por advogado ou defensor público. A escritura pública constitui título hábil para o registro imobiliário ${ }^{6}$, (art. $610, \S \S 1^{\circ}$ e $2^{\circ}$, do Código de Processo Civil).

Além dessas formas, tem-se o inventário conjunto, que ocorre quando abranger mais de um espólio, como por exemplo, se o cônjuge meeiro falecer antes do pré-morto, ou seja, antes da abertura da sucessão, e os herdeiros forem os mesmos. (CPC, art. 672) ${ }^{7}$ e, antes da partilha

3 CPC/1973 - arts. 982 a 1.021

4 CPC/1973 - art. 1.031, com a nova redação da Lei n. 11.441/2007

${ }^{5} \mathrm{CPC} / 1973$ - art. 1.036 - cabível quando os bens do espólio forem de valor igual ou menor 2.000 OTN.

${ }^{6} \mathrm{CPC} / 1973$ - art. 982 - Lei n. 11.441 de 04.01.2007

${ }^{7} \mathrm{CPC} / 1973$ - art. 1.043 
falecer um dos herdeiros, que não possui outros bens e o inventário negativo judicial e extrajudicial, o qual será objeto de investigação pormenorizada a seguir.

\section{O INVENTÁRIO NEGATIVO}

O inventário negativo, sem previsão na legislação pátria, segundo Itabaiana de Oliveira, citado por Diniz (2018, p. 444), tem sido admitido como um "modo judicial de se provar, para determinado fim, a inexistência de bens a inventariar".

Oliveira e Amorim (2013, p. 278) anotam que, em situações excepcionais, o inventário negativo tem por finalidade "comprovar a inexistência de bens a inventariar, objetivando o acertamento de determinada situação pessoal ou patrimonial do viúvo ou de terceiro". (OLIVEIRA; AMORIM, 2013, p. 278). O inventário negativo é uma das modalidades de inventário e "tem por objetivo provar que o herdeiro não herdou nenhum bem do falecido". (CASSETTARI, 2012, p. 183).

Rodrigues (2007, p. 290), com sua peculiar didática, assevera que se inventariar é relacionar bens, descrevê-los, discriminar dívidas, ou seja, “é uma relação, um rol, uma listagem. Inventário negativo é uma expressão contraditória, em que o segundo vocábulo briga com o primeiro". A respeito da “expressão contraditória”, Pereira (2014, p. 364) comenta: o inventário "consistindo em uma relação de bens deixados pelo finado, somente poderia ser positivo. A ausência de bens é a negação do inventário, e, portanto, se a pessoa morre sem nada de seu, caso seria de não se proceder a qualquer medida”.

No entanto, "tanto a expressão quanto a figura processual respectiva introduziram-se em nosso direito, por praxe forense há longo tempo estabelecida, para atender necessidades práticas. O inventário negativo não foi previsto em nossas leis, mas faz parte do costume jurídico". (RODRIGUES, 2007, p. 290).

$\mathrm{Na}$ prática, para parte da doutrina e jurisprudência, existem situações em que se recomenda o processamento do inventário negativo. Isso ocorre, por exemplo, com a situação prevista no Código Civil, art. 1.641, inciso I, combinado com o art. 1.523, I, a qual impõe o regime de separação de bens no casamento do viúvo ou viúva que tenha filhos do cônjuge falecido. Tal imposição pode ser levantada se o cônjuge sobrevivente fez inventário e deu partilha aos herdeiros. "Se o extinto casal não possuía haveres, nada impede a comunhão pretendida, que vigorará nas segundas núpcias, a não ser que haja pacto antenupcial ao contrário". Para casos como esse, apesar de a lei não dispor sobre o inventário negativo, "a doutrina e a jurisprudência o consideram necessários (RF, 74:31, 130:303, 102:292; RT, 
268:300, 488:97), para que o cônjuge viúvo fique isento da penalidade e do impedimento mencionado". (DINIZ, 2018, p. 444) ${ }^{8}$. Na sequência, a autora apresenta o procedimento para o requerimento por parte do cônjuge viúvo:

\begin{abstract}
Assim, o consorte viúvo, segundo a praxe, apresentará ao magistrado um requerimento dentro do prazo legal do art. 1.796 do Código Civil; porém, se ultrapassar de muito esse prazo, qualquer interessado poderá exigir que prove suas alegações por meio de testemunhas, instruído com a certidão de óbito, mencionado o nome do inventariado, dia e lugar do falecimento, os nomes, as idades, o estado civil e a residência dos herdeiros, declarando a inexistência de bens por inventariar e partilhar. O magistrado mandará o viúvo afirmar a verdade do conteúdo de sua petição, mediante o respectivo termo, e dar vista dos autos, em curto prazo, aos herdeiros, aos representantes da Fazenda Pública e aos curadores e órfãos e ausentes, se houver herdeiro menor, interdito ou ausente. Ouvido os interessados, estando todos de acordo, o juiz proferirá sentença, proclamando a negatividade do inventário. Essa decisão será trasladada, mediante certidão, aos autos de habilitação do matrimônio. (DINIZ, 2018, p. 444).
\end{abstract}

A situação do viúvo ou da viúva, que tem filhos do extinto casal, e pretende convolar novas núpcias, não é a única que concorre para o processamento do inventário negativo, posto que existem outras hipóteses nas quais o citado inventário pode ser útil e servir para dar certeza e segurança às diversas situações, tais como, no caso de "haver o interesse do sucessor na comprovação de que não deixou o falecido com que atender aos seus credores, 'o que é da maior relevância no plano das responsabilidades, uma vez que o herdeiro somente responde intra vires hereditatis" (RODRIGUES, 2007, p. 291, itálicos do autor); do divorciado, enquanto não homologada ou decidida a partilha dos bens do casal (art. 1.523, III, do Código Civil), o parágrafo único do citado art. 1.523, "permite aos nubentes solicitar ao juiz que não lhes sejam aplicadas as causas suspensivas", se provarem a inexistência de prejuízo para os herdeiros, e uma "das formas de efetuar essa prova será exatamente o inventário negativo, ainda que se lhe empreste outro nome, como justificativa ou escusa da causa suspensiva"; do disposto no art. 1.792, da mesma legislação ordinária, que determina que o "herdeiro não responde por encargos superiores às forças da herança; incumbe-lhe, porém, a prova do excesso, salvo se houver inventário que a escuse, demonstrando o valor dos bens herdados", também, nesse caso, o interessado poderá comprovar judicialmente a inexistência ou insuficiência dos bens em nome do de cujus. (OLIVEIRA. AMORIM, 2013, p. 279).

\footnotetext{
8 Nesse mesmo sentido, "o inventário negativo se torna, em certos casos, de suma importância, constituindo mesmo uma necessidade imperiosa, pois evita a imposição de certas penas com que o Código Civil castiga a infração de algumas" de suas disposições (OLIVEIRA; AMORIM, 2013, p. 278), e, em sentido contrário, Rodrigues (2007, p. 291) colaciona a decisão na qual a "falta do chamado 'inventário negativo' não acarreta, por si mesma, o regime de separação de bens no segundo casamento uma vez provado que notoriamente não havia bens a inventariar' (RT, 549/217)".
} 
Situação análoga de inventário sem bens a partilhar, segundo Oliveira e Amorim (2013, p. 279), acontece na hipótese de o defunto deixar apenas obrigações por cumprir, como "a de outorga de escritura a compromissários compradores de imóveis vendidos e quitados anteriormente à abertura da sucessão. O procedimento judicial servirá de meio para que se nomeie inventariante a fim de dar cumprimento a essa obrigação deixada pelo espólio”.

Além da doutrina, o inventário negativo encontra "tranquilo suporte na jurisprudência (RT 488/97 e 639/79)”. (OLIVEIRA; AMORIM, 213, p. 278). Em outros recentes julgados colacionados consta: “[...] Pleito ajuizado por filhos que pretendem a declaração de inexistência de patrimônio da genitora falecida [...]" (TJSP; APL 1028341-07.2015.8.26.0224; Ac. 9115627; $3^{\text {a }}$ C.D. Priv.; Rel. Des. Dácio Tadeu Viviani Nicolau; DJESP 16.02.2016); “[...] Ainda que o falecido não deixe bens a inventariar, é possível a abertura de inventário negativo que, à mingua de regulamentação legal, é um procedimento utilizado para declarar que nada há a inventariar [...]"(TJMJ; APCV 1.0312.17.001867-4/001; 4ª C.Civ.; Rel. Des. Renato Dresch; DJEMG 03.04.2018).

\section{INVENTÁRIO EXTRAJUDICIAL: NEGATIVO}

A Lei n. 11.441/2007 tem o fito de “desjudicializar o cotidiano', como diz Regnoberto M. de Melo Jr., notarizando-o, ao alterar o art. 982 do Código de Processo Civil/1973, prevendo a possibilidade de optar pelo procedimento administrativo de inventário e partilha". (DINIZ, 2018, p. 444-445). Ainda, segundo a autora, “O inventário judicial submete-se às normas de competência do art. 48 do Código de Processo Civil e o extrajudicial, à Lei 8.935/94 ${ }^{9}$, por ser norma especial e ao CPC, arts. 610, $\S \S 1^{\circ}$ e $2^{\circ}$. (DINIZ, 2018, p. 445).

Acerca do inventário extrajudicial e do processo de desjudicialização, Figueiredo (2015, p. 89) argumenta que:

A partir da Lei n. 11.441/2007, o direito positivo brasileiro passou a admitir que os inventários e as partilhas, na sucessão, fossem celebrados e formalizados através de escritura pública, lavrada por tabelião de notas. A escritura pública de inventário passou, assim, a representar, desde essa Lei, o título hábil para o registro de transferência de bens, móveis e imóveis, de direitos em virtude de sucessão, sem a intervenção do magistrado, em processo judicial, no âmbito da jurisdição das varas cíveis especializadas em matéria sucessória. Vale observar que tal alteração representou uma efetiva revolução, das mais relevantes, no direito processual brasileiro, no que tange a desjudicialização dos assim denominados atos de jurisdição voluntária. $\mathrm{O}$ avanço no processo de

\footnotetext{
${ }^{9}$ Regulamenta o art. 236 da Constituição Federal de 1988, dispondo sobre serviços notariais e de registro. (Lei dos Cartórios)
} 
desjudicialização pode ser apontado como consequência ou reação objetiva ao grave congestionamento da justiça nos tempos atuais.

O atual Código de Processo Civil trouxe "importantes mecanismos de pacificação por intermédio das serventias extrajudicial" (SILVA; BARROS, 2016, p. 193), em seu art. 610, §§ $1^{\circ}$ e $2^{\circ}$, prevê sobre o inventário extrajudicial, nos seguintes termos:

\footnotetext{
Art. 610. Havendo testamento ou interessado incapaz, proceder-se-á ao inventário judicial.

$\S$ 1 Se todos forem capazes e concordes, o inventário e a partilha poderão ser feitos por escritura pública, a qual constituirá documento hábil para qualquer ato de registro, bem como para levantamento de importância depositada em instituições financeiras.

§ 2ํ O tabelião somente lavrará a escritura pública se todas as partes interessadas estiverem assistidas por advogado ou por defensor público, cuja qualificação e assinatura constarão do ato notarial.
}

A Lei n. 11.441/2007 é composta por cinco artigos, quatro "dos quais de cunho normativo - arts. $1^{\circ}$ a $3^{\circ}$ e $5^{\circ}$ ". E somente "um de cunho formalista, o art. $4^{\circ}$ trata da formalidade legislativa, aduzindo à vocatio legis e informando que a entrada em vigor da norma se inicia desde a sua publicação no DOU, conferindo-lhe aplicabilidade imediata desde os dias 5 de janeiro de 2007”. (PARODI; SANTOS, 2007, p. 123).

A Resolução do Conselho Nacional de Justiça n. 35/2007 disciplina a aplicação da Lei n. 11.441/2007, pelos serviços notariais de registro. Segundo consta nas disposições gerais da Resolução em comento, é livre a escolha do tabelião de notas, inclusive em qualquer estado da federação, e não se aplicam as regras de competência do Código de Processo Civil para a lavratura dos atos notariais de que trata a Lei $\mathrm{n}^{\circ} 11.441 / 07$, a qual não impede a utilização da via judicial pelos interessados, apenas faculta a opção pela via extrajudicial, desde que preenchidos os requisitos legais, "podendo ser solicitada, a qualquer momento, a suspensão, pelo prazo de 30 dias, ou a desistência da via judicial, para promoção da via extrajudicial" (art. $2^{\circ}$ ). As escrituras previstas no art. $610, \S 1^{\circ}$, do CPC não dependem de homologação judicial e "são títulos hábeis para o registro civil e o registro imobiliário, para a transferência de bens e direitos, bem como para promoção de todos os atos necessários à materialização das transferências de bens e levantamento de valores (DETRAN, Junta Comercial, Registro Civil de Pessoas Jurídicas, instituições financeiras, companhias telefônicas, etc.)” (art. 3); o valor dos emolumentos e a gratuidade dos atos também estão previstos nos arts. $4^{\circ}$ e $5^{\circ}$ da mesma Resolução; a assistência de advogados e defensores é obrigatória, e desnecessária a juntada da procuração, assim como ao tabelião é vedada a indicação de advogados às partes; à parte 
hipossuficiente é facultada a assistência pelas Defensorias Públicas e OAB, onde existirem; finalmente, segundo consta no art. 10, da Resolução n. 35/2007:

É desnecessário o registro de escritura pública decorrente da Lei ${ }^{\circ}$ 11.441/2007 no Livro "E" de Ofício de Registro Civil das Pessoas Naturais, entretanto, o Tribunal de Justiça deverá promover, no prazo de 180 dias, medidas adequadas para a unificação dos dados que concentrem as informações dessas escrituras no âmbito estadual, possibilitando as buscas, preferencialmente, sem ônus para o interessado.

A Seção II, da Resolução 35/2007, traz disposições específicas referentes ao inventário e à partilha e em seu art. 28 admite o inventário negativo por escritura pública, com a seguinte redação: "É admissível inventário negativo por escritura pública". Nesse diapasão, a doutrina também admite a possibilidade do inventário negativo por escritura pública. (DINIZ, 2018, p. 444; JUNQUEIRA; CARVALHO, 2018, p. 216).

Nesse sentido, Cassettari (2012, p. 183), igualmente, compreende haver a possibilidade de se realizar o inventário negativo mediante escritura pública, sob os seguintes argumentos: "a lei não estabeleceu qual das modalidades de inventário poderá ser objeto de escritura pública, mas tão somente exigiu que todos os interessados fossem capazes e concordes". Portanto, continua o autor, uma vez preenchidos os requisitos, "não haveria impossibilidade de se fazer o inventário negativo por escritura, considerando ser esse necessário", nas hipóteses de completa insolvência do falecido e no caso de o cônjuge sobrevivente desejar casar-se novamente e "não sofrer restrições quanto à escolha do regime de bens".

Cassettari (2012, p. 184) levanta duas questões que surgem quando se adota posicionamento favorável. A primeira diz respeito à necessidade de assistência de advogado para tal ato e a segunda, diante da existência de interessado incapaz, se se poderia ser feito por escritura pública o inventário negativo. Quanto à primeira questão, o autor compreende que sim, há a necessidade de advogado, por se "tratar de aplicação analógica da Lei 11.441/2007, que instituiu a possibilidade de se realizar o inventário por escritura pública, em razão da referida lei exigir a assistência de advogado" e a segunda, da mesma forma que a primeira, entende que "sim, haja vista que não existirá bem jurídico a ser tutelado, motivo pelo qual não haverá a necessidade de o incapaz ser protegido pelo Ministério Público".

\section{CONSIDERAÇÕES FINAIS}

À guisa de conclusão é possível afirmar que os procedimentos judiciais para a relacionar, descrever, avaliar e liquidar os bens pertencentes ao de cujus são bastante antigos 
em nossa legislação. Apesar disso, o procedimento para provar a inexistência de bens do falecido, inventário negativo, não é previsto pela lei. Essa tarefa cabe, mais uma vez, à doutrina e à jurisprudência, e no caso do inventário extrajudicial, ao Conselho Nacional de Justiça.

No inventário negativo não se visa inventariar nada, o que se procura é, tão somente, obter uma sentença homologatória que, após citados os herdeiros, caso não haja impugnação, pedido de colação ou alegação de bens sonegados, declare não haver o que inventariar.

Na prática, isso ocorre, na maioria das vezes, para proporcionar segurança jurídica ao prevenir direitos das pessoas interessadas. Observa-se no sentido empregado ao termo sucessor - aquele que herda um patrimônio -, no inventário negativo não se trata de sucessores e sim de pessoas interessadas, porque tinham algum tipo de negócio jurídico com o de cujus.

No tocante ao inventário extrajudicial, verifica-se que houve pouca alteração. Desde a entrada em vigor da Lei n. 11.441/2007, o atual Código de Processo Civil apenas alterou a redação do inventário e partilha extrajudiciais previstas no Código de Processo Civil de 1973 e deixou à deriva questões como a possibilidade de, mesmo havendo testamento válido, se recorrer às vias extrajudiciais. Assim, os maiores avanços, ainda, ficam a cargo da possibilidade de os Cartórios servirem de instrumento para a desjudicialização do processo, ou seja, de não se levar a juízo alguns procedimentos de jurisdição voluntária.

A discussão acerca da possibilidade ou não do inventário negativo encontra-se superada, uma vez que os dados apontaram, com clareza, que apesar de o inventário negativo judicial ou extrajudicial não ser recepcionado pela legislação brasileira, na praxe, ele encontra guarida na doutrina, na jurisprudência e no art. 28 da Resolução n. 35/2007 do Conselho Nacional de Justiça $(\mathrm{CNJ})$.

As considerações de Pontes de Miranda, citadas na epígrafe, no sentido de que “inventário é a declaração do conhecimento, em que se descreve e enumera ou só se descreve o que se encontrou", é possível, com toda vênia, acrescentar, "ou só se descreve o que" não se encontrou.

\section{REFERÊNCIAS}

CASSETARI, Christiano. Separação, divórcio e inventário por escritura pública: teoria e prática. São Paulo: Método, 2012.

DINIZ, Maria Helena. Curso de direito civil brasileiro. Direito das sucessões. 32. ed. São Paulo: Saraiva, 2018. v. 6. 
ECO, Umberto. Como se faz uma tese. Tradução de Gilson Cesar Cardoso de Souza. 23. ed. São Paulo: Perspectiva, 2010.

FIGUEIREDO, Ivanildo. Inventário extrajudicial na sucessão testamentária: possibilidade, legalidade, alcance e eficácia. Revista Nacional de Direito de Família e Sucessões. Porto Alegre, v. 8, p. 89-116, set./out., 2015.

JUNQUEIRA, Gabriel José Pereira; CARVALHO, Luís Pereira Batista de. Manual prático de inventários e partilhas. 14. ed. Leme: Mundo Jurídico, 2018.

MARCHI, Eduardo C. Silveira. Guia de metodologia jurídica. 2. ed. São Paulo: Saraiva, 2009.

OLIVEIRA, Euclides Benedito de, AMORIM, Sebastião Luiz. Inventários e Partilhas: direito das sucessões. 23. ed. rev. e atual, São Paulo: Livraria e Editora Universitária de Direito, 2013.

PACHECO, José da Silva. Inventários e partilhas na sucessão legítima e testamentária. 18. ed., rev. e atual. Rio de Janeiro: Forense, 2005.

PARODI, Ana Cecília de Paula-Soares; SANTOS, Clarice Ribeiro dos. Inventário e rompimento conjugal por escritura: praticando a lei n. 11.441/2007. 2. ed. Campinas: Russell Editores, 2007.

PEREIRA, Caio Mario da Silva. Instituições de direito civil. 21. ed. rev. e atual. por Carlos Roberto Barbosa Moreira. Rio de Janeiro: Forense, 2014. v. VI.

PONTES DE MIRANDA, Francisco Cavalcanti. Tratado de direito privado. 4. ed. São Paulo: RT, 1984. t. 60.

RODRIGUES, Silvio. Direito civil: Direito das sucessões. 26. ed. rev e atual. por Zeno Veloso. São Paulo: Saraiva, 2006. v. 7

SEVERINO, Antônio Joaquim. Metodologia do trabalho científico. 4. ed. rev. São Paulo: Cortez \& Moraes Ltda, 1979.

SILVA, Érica Barbosa e; BARROS, Giovanna Truffi Rinaldi de. O novo CPC e o inventário extrajudicial uma análise crítica. Revista Nacional de Direito de Família e Sucessões. Porto Alegre, v. 10, p. 193-202 jan./fev., 2016.

SILVA, De Plácido. Vocabulário jurídico. 7. ed. Rio de Janeiro: Forense, 1982. v. II.

Trabalho recebido em 01 de abril de 2019

Aceito em 07 de junho de 2020 